\title{
LOS PLANES FEDERALES DE VIVIENDA EN EL ÁREA METROPOLITANA DE BUENOS AIRES
}

\section{FEDERAL HOUSING PLANS IN THE METROPOLITAN AREA OF BUENOS}

AIRES

v. 9, n. 1 [15]

jan/abr (2017)

Dossiê "Villas Miseria, Favelas y Asentamientos: nuevas rutas en Historia Urbana"
María Mercedes Di Virgilio; Florencia Aramburu; Camila Chiara Instituto de Investigacones Gino Germani, UBA mercedes.divirgilio@gmail.com; floraramburu90@hotmail.com; cami.chiara@hotmail.com

\section{Resumen}

El objetivo del artículo es reflexionar en torno a la implementación de políticas habitacionales en el Conurbano Bonaerense, particularmente los Planes Federales, en relación con las políticas habitacionales implementadas en la región en los últimos años. El análisis se construye, mediante datos secundarios, a partir de una desagregación minuciosa de las características que estos Programas adquirieron en cada municipio en el período comprendido entre el anuncio oficial y principios del 2014. En este sentido, busca iluminar qué municipios implementaron estas políticas, mediante qué subprograma lo hicieron, qué tipología de obras ejecutaron, y en qué estado de avance se encuentran. Ello a partir de la puesta en diálogo con la situación habitacional que presenta el Conurbano Bonaerense.

\section{Palabras claves}

Políticas habitacionales. Programas federales de vivienda. Conurbano bonaerense.

\section{Abstract}

The aim of this article is to consider the implementation of housing policies in the Conurbano Bonaerense, specially the Federal Plans, in relation to the housing policies implemented in the region during recent years. The review is constructed, using secondary data, from a detailed breakdown of the characteristics that these programs acquired in each municipality, during the period from the official announcement and the beginning of 2014. In this sense, seeks to illuminate what municipalities implemented these policies, by what subprogram they did, what 
type of building they carried out, and in what condition of progress they are. This from the continue dialogue with the housing situation that the Conurbano Bonaerense presented.

\section{Keywords}

Housing policies. Federal housing programs. Conurbano bonaerense.

\section{Introducción}

Luego de décadas marcadas por la escasa intervención pública en materia habitacional, el Plan Federal de Vivienda, lanzado en 2003 por el entonces presidente Néstor Kirchner, impulsa un giro re-centralizador de la política habitacional, al ritmo de nuevos programas de vivienda y de infraestructura urbana. Si bien -tal como señaláramos en trabajos anteriores (véase DI VIRGILIO; RODRÍGUEZ; MERA, 2016)-, la política de los Planes Federales sigue los cánones de los programas y de experiencias urbanísticas presentes en varias ciudades latinoamericanas (DELGADILLO, 2014); el aspecto verdaderamente novedoso del caso Argentino es que dicha política restituyó la cuestión de la vivienda en la agenda pública, reposicionando al Estado como actor clave en el sector, en virtud del volumen de recursos destinados y de soluciones habitacionales producidas (Figura 1 ).

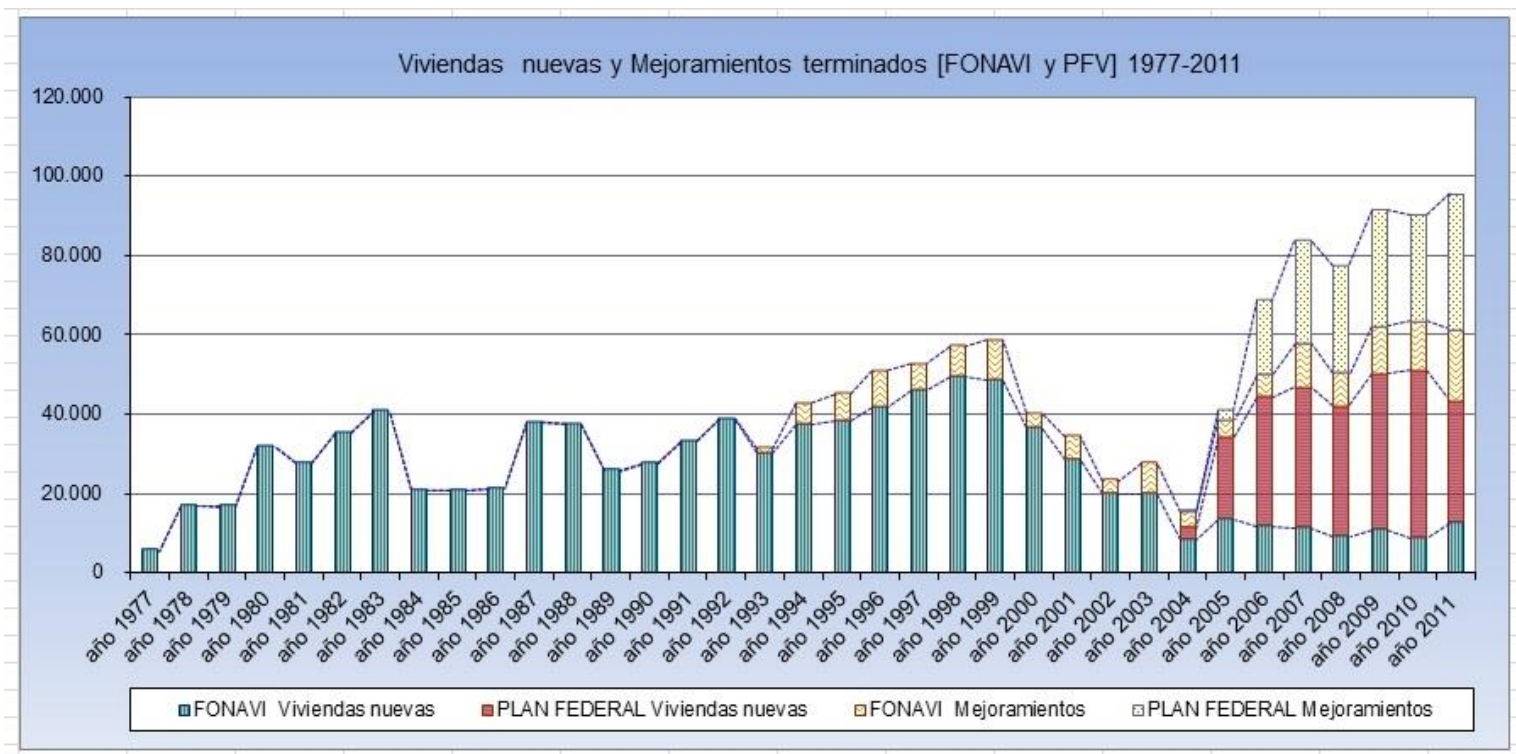

Figura 1: Evolución de la producción habitacional 1977-2011 ${ }^{1}$

Fuente: RODULFO y BOSELLI (2014, p.224) Con base en Auditoria FONAVI y Planes Federales Ejercicio 2010 y Revistas del CONAVI, Nº1 del año 2000 a No 39 de abril de 2013.

${ }^{1}$ Se han considerado "viviendas terminadas" a aquellas que han contado con recepción provisoria durante el ejercicio o bien las que, no contando con ésta por diferentes circunstancias, se han liberado al uso de los beneficiarios. 
La centralidad que adquirió la política de vivienda en el país abre algunos interrogantes acerca de su implementación en el aglomerado más densamente poblado: el Área Metropolitana de Buenos Aires. En este marco, el artículo pasa revista a y nos brinda herramientas para reflexionar sobre 1) rol del Estado, en sus diferentes niveles, en la planificación e implementación de los proyectos urbanos que se gestionaron a partir de los Programas Federales; 2) la correlación entre el tipo de déficit habitacional específico soportado y la política urbana implementada y 3) la existencia (o no) de una política de suelo y de otras medidas que acompañan el desarrollo de dichos programas.

\section{Los Planes Federales de Vivienda en el marco de las políticas regionales}

La política de los Planes Federales no constituye una política novedosa. Lejos de ello, sigue los lineamientos de los programas iniciados en la región durante la década de 1980. En términos generales, se trata de una política masiva de construcción de vivienda fuertemente articulada en su implementación, con iniciativas de mercado y sectores concentrados de la industria de la construcción.

El precursor de dichas iniciativas en la región fue, sin dudas, Chile. Allí el Ministerio de Vivienda y Urbanismo, con la Cámara Chilena de la Construcción, produjo vivienda social para el $12 \%$ de la población del país, unas seiscientas mil familias, entre 1980 y el 2006. El modelo de producción -y de financiamiento- fue fuertemente difundido en otros países de América Latina, y diversos organismos internacionales (Banco Interamericano de Desarrollo, PNUD, Cepal) se dedicaron a resaltar mediante cifras y estadísticas los logros del mecanismo virtuoso que combinaba ahorro, subsidio y crédito (RODRÍGUEZ; SUGRANYES, 2011). Sin embargo, poco se resaltó la contracara: por esta vía la resolución del problema de los "sin techo" trajo aparejada la creación del problema de los "con techo" (RODRÍGUEZ; SUGRANYES, 2005). El subsidio habitacional chileno posibilitó un mecanismo de financiamiento en donde convergieron actores públicos y privados, materializados en la formula virtuosa: subsidio - ahorro - crédito. Compuesto por el Estado que brindaba el subsidio habitacional, los "beneficiarios" personificados en las familias que ahorraban y tomaban un crédito para la vivienda y, las empresas constructoras que se habían especializado en el rubro de las viviendas baratas; fórmula que tuvo como resultado el lucro financiero asegurado.

En la práctica, el Estado realizaba licitaciones para la presentación de proyectos que proveyeran suelo y vivienda; de este modo, la empresa constructora definía la localización que tendría la vivienda social que, al estar guiada por la lógica de la ganancia, se inclinaría por ofrecer los terrenos de menor costo posible, situados en la periferia y que pudieran generar rentabilidad futura en las parcelas aledañas. Consecuentemente, el modelo, que desdibuja el rol de Estado cediendo al mercado el criterio del desarrollo urbano en la ciudad, produjo viviendas sin equipamiento, en la lejanía de los centros productivos y con escases de áreas de recreación 
formando manchas urbanas con concentración homogénea de pobreza (HIDALGO DATTWYLER, 2007; RODRIGUEZ; SUGRANYES, 2005).

El modelo chileno, que implicó el corrimiento del Estado desde la producción de la urbanización hacia el rol de facilitador para su producción por parte del mercado inmobiliario, también puede observarse en México a partir de la última década del siglo XX. En éste caso, el Estado articuló su corrimiento de la función reguladora del diseño, la planificación y la implementación de los programas de desarrollo habitacional con la liberalización de las tierras ejidales al mercado urbano -fruto de las reformas de 1992 a la Constitución y a la Ley Agrariaque permitieron que los promotores inmobiliarios se apropiasen del suelo de las comunidades agrarias a bajo precio (SALAZAR, 2013). De este modo, en los años '90, la desregulación de la política habitacional recomendada por el Banco Mundial permitió que las empresas privadas quedaran a cargo de la producción del suelo, el financiamiento inicial, la producción de infraestructura y, la construcción y comercialización de las viviendas. Asimismo, la reforma constitucional posibilitó que las tierras comunitarias localizadas en las periferias urbanas se convirtiesen en campo fértil para la captación de renta por medio de la valoración de dicho suelo en forma privada (PÍREZ, 2014).

En este marco, el rol del Estado mexicano quedó reducido a otorgar préstamos hipotecarios a los "derechohabientes" -que entre 2001 y 2011 llegaron a sumar 7 millones de créditos para vivienda nueva-. El giro en la política fue sostenido desde el discurso oficial esbozando que "la continua y creciente demanda habitacional debía ser resuelta por el mercado formal y a través de la construcción de vivienda nueva, lo cual además, constituía un "buen estímulo a la economía" (SALAZAR, 2013, p.8). En tanto, la producción de la vivienda social financiada por el Estado, en manos de los desarrolladores inmobiliarios, era orientada por la lógica de la ganancia, con efectos en la localización de los conjuntos (periférica), el tamaño (la gran escala permitió bajar los costos) y la baja calidad de la vivienda. Al hacerse evidentes sus resultados, el modelo de subsidio habitacional descripto fue fuertemente criticado desde las ciencias sociales, entre las principales falencias referidas nos encontramos con: 1) el corrimiento del Estado del rol de planificador de los proyectos urbanos, permitiendo que los desarrolladores decidieran bajo una lógica especulativa la ubicación, las obras de infraestructura pertinentes, el tamaño de los complejos, es decir, construyeran la ciudad; 2) la ausencia de actores sociales guiados por la lógica de la necesidad en la planificación o la implementación de las políticas urbanas, las mismas estuvieron enfocadas en el rol del "beneficiario", excluyendo a organizaciones sociales y cooperativas con capacidad de negociación y de desarrollo de proyectos urbanos; 3 ) la no correlación entre el tipo de déficit habitacional soportado y la política urbana implementada -ante la existencia de un amplio parque de viviendas deficitarias y de hogares con hacinamiento, la política se centró en la construcción de vivienda nueva en la periferia, desestimando las obras de mejoramiento y la atención sobre los inmuebles vacíos ubicados en las centralidades-; y 4) la falta de una política de suelo que acompañase el desarrollo 
de dichos programas, facilitando las sobreganancias por parte del sector de la construcción y las empresas desarrolladoras, multiplicando la segregación en las ciudades latinoamericanas; es decir, las políticas urbanas relegaron la función social del suelo y posibilitaron su usufructo privado.

A pesar de la experiencia acumulada en Chile y en México, recientemente, en el contexto de las crisis socioeconómicas vividas en los países de la región en las postrimerías del siglo XX, las iniciativas de producción masiva de vivienda reaparecen de la mano de las llamadas políticas habitacionales "contracíclicas". Un ejemplo de ello es el Programa "Minha Casa, Minha Vida" en Brasil, un país que se caracterizó por una política urbana activa, con importantes logros en el esquema normativo e institucional observable en el Estatuto de la Ciudad (aprobado en 2001) y en el Ministerio de las Ciudades (creado en 2003). La aprobación del Estatuto fue entendida como una conquista en el camino de la Reforma Urbana; ya que el mismo dispone de instrumentos legales que permiten poner en vilo la especulación inmobiliaria, posibilitando la ocupación de áreas ya dotadas de infraestructura y equipamientos -es el caso del Impuesto a la Propiedad Predial y Territorial Urbana-, y revindica la participación de los movimientos sociales en los procesos de decisión sobre el espacio urbano (DE SOUZA; DE LA MORA; CAVALCANTI, 2013).

Con todo, frente a la crisis mundial de 2008 el gobierno de Lula Da Silva es presionado por las empresas constructoras brasileñas ${ }^{2}$ y en el primer semestre de 2009 es anunciado el plan de salvataje "Minha Casa, Minha Vida". El programa fue planificado por la Casa Civil y por el Ministerio de Hacienda de Brasil en negociación con representantes de los sectores inmobiliarios y de la construcción, ignorando los alcances institucionales obtenidos en el área de la gestión urbana y excluyendo la articulación con otros actores de la sociedad civil. En la práctica, el programa implicó la inyección de alrededor de 100 mil millones de reales, para la construcción de 3 millones de viviendas, reproduciendo el modelo de oferta de mercado aplicado en México y Chile. El monto de los recursos públicos, proponía un subsidio alto para los hogares de menores ingresos, la franja que iba de 0 a 3 sueldos mínimos, que podía alcanzar el eslogan de "la vivienda propia" por un mínimo de 50 reales por mes; sin embargo, la familia recibía una casa de $35 \mathrm{~m}^{2}$ y ubicada en la periferia extrema. A su vez, el direccionamiento del programa hacia las empresas privadas fue casi total, el $97 \%$ se orientó a la oferta y producción directa por parte de constructoras, destinando solo el $3 \%$ a movimientos sociales, cooperativas u organizaciones sociales en general. Evidentemente, al igual que en los modelos presentados, el poder público se corrió de la presentación de proyectos, los mismos no fueron licitados, ni definidos como parte de una estrategia estatal o municipal de desarrollo urbano, que permitiera

2 Para una mayor comprensión del sentido que encubrió la creación del Programa ver "Reforma Urbana y autogestión en la producción de la ciudad" (HIGUCHI HIRAO; GUERREIRO; FIORI ARANTES; BARBOSA DE OLIVEIRA, 2013). 
fortalecer las estructural locales en la gestión o en el control del uso del suelo; asimismo, el Programa tampoco permitió la participación de organizaciones sociales (HIGUCHI HIRAO; GUERREIRO; FIORI ARANTES; BARBOSA DE OLIVEIRA, 2013). A su vez, al 2011, el programa no incluía un repertorio de acción sobre los inmuebles vacíos ${ }^{3}$, unidades habitacionales que en su mayoría cuentan con infraestructura urbana completa y equivalen al $83 \%$ del déficit habitacional (6 millones de unidades al 2011). De este modo, el Programa encuentra múltiples puntos de contacto con el modelo chileno, que Sugranyes et al. (2012) definió de forma esclarecedora como un "subsidio a la oferta"; dado que se esconde tras un subsidio habitacional, pero en la práctica implica una transferencia de recursos públicos al sector inmobiliario y de la construcción, asignación garantiza la construcción de conjuntos habitacionales de bajo costo y asegura una ganancia dirigida.

Las múltiples experiencias, dan cuenta de un conjunto de acciones, planes y programas que constituyen las "recetas probadas" (DELGADILLO, 2014) en distintos contextos socioeconómicos, políticos y urbanos para confrontar algunos desafíos urbanos comunes. El caso argentino no se aleja demasiado de estas experiencias, por el contrario, las mismas son el telón de fondo en el que se debe enmarcar toda reflexión sobre las políticas habitacionales implementadas en Argentina en la última década, específicamente los Planes Federales.

\section{Los programas habitacionales en Argentina}

La reincorporación de la cuestión habitacional a la agenda pública, en el año 2003 durante la presidencia de Néstor Kirchner, provocó un rotundo giro en materia de políticas habitacionales que persiguió tres objetivos: la generación de empleo, la disminución del déficit habitacional y la reactivación de la economía local a partir de la movilización del mercado de la construcción4. Estos objetivos fueron puestos en práctica por medio de diversos programas, conocidos como los Planes Federales de Vivienda. Dichas iniciativas innovarán en su organización centralizada, restringiendo el escenario de acción para los gobiernos provinciales y municipales en lo que respecta a la ejecución de políticas públicas propias. "En la poscrisis, ni las provincias ni los municipios cuentan con recursos presupuestarios propios y específicos que les permitan cierta movilidad por fuera de los lineamientos establecidos a nivel nacional" (RODRÍGUEZ; DI VIRGILIO, 2011, p.71)

El primer Programa puesto en funcionamiento en este contexto es el Programa Federal de Emergencia Habitacional o "Techo + Trabajo". El cual combina, por un lado, el objetivo de construcción de viviendas y por el otro, el de generación de empleo, a la vez que articula

3 La segunda etapa del Programa, lanzada en el 2011, contó con recursos para reformas en los inmuebles vacíos, aunque no se ha encontrado casos en donde se detalle su implementación. 
instancias gubernamentales como ser: el Ministerio de Planificación Federal, Inversión Pública y Servicios de la Nación; la Subsecretaria de Desarrollo Urbano y Vivienda; el Ministerio de Desarrollo Social y el Instituto Nacional de Economía Social y Solidaria. Este Programa se orienta a la construcción de viviendas a partir de cooperativas de trabajo conformadas por los beneficiaros del Programa Jefas y Jefes de Hogar, lo que indica que incluye organizaciones sociales en su desarrollo y ejecución.

Posteriormente, en el 2004, el Gobierno Nacional lanza el Programa Federal de Mejoramiento de Viviendas y el Plan Federal de Construcción de Viviendas. El primero de ellos, conocido como "Mejor Vivir", se origina como consecuencia de la valoración del déficit habitacional arrojado por los datos del Censo 2001, el cual reflejaba la existencia de un importante stock de viviendas deficitarias. Por lo tanto, el objetivo de dicho Programa será abordar las obras de refacción, completamiento y ampliación en viviendas familiares entre sectores que se vieran imposibilitados de acceder a un crédito. El monto total a financiar en su primer lanzamiento fue de U\$S 485.385 .000 con el propósito de cubrir el mejoramiento de 140.000 viviendas. Particularmente, en el Partido de Gran Buenos Aires, se buscaba cubrir la optimización de 32.640 viviendas, destinando U\$S 3.378 por unidad, es decir, el 22,40\% del total del presupuesto.

El segundo de ellos, el Programa Federal de Construcción de Viviendas (PFCV) es la política pública en materia habitacional de mayor escala desarrollada en la región en las últimas dos décadas. El mismo plasma, el giro estatal en relación a las problemáticas de hábitat, en general, y de vivienda, en particular (OSTUNI, 2007). En el primer lanzamiento, la Nación, por medio del Ministerio de Infraestructura y Planificación Federal y la Subsecretaría de Urbanismo y Vivienda, se comprometió ante las provincias y la Ciudad Autónoma de Buenos Aires a otorgar un financiamiento no reintegrable para la construcción en todo el país de ciento veinte mil unidades de vivienda (lo que equivaldría a U\$S 1.291.666.667) ${ }^{5}$. Fondo que se encontraba orientado a la construcción de vivienda con infraestructura y con una superficie cubierta mínima, localizadas, un tercio de ellas, en el AMBA.

A partir de la experiencia del Programa Federal I, la Nación lanzó durante el año 2007, el Programa Federal II, con una inversión de U\$S 5.488.958.990 para la construcción de 300.000 viviendas. En ambos casos se otorgaban tareas de implementación y ejecución del proyecto a los gobiernos locales, es decir, les confiere un rol central para la ejecución de las políticas de vivienda; por lo cual, para que el programa se implemente los gobiernos locales deben diseñar proyectos de intervención, gestionar su financiamiento, confeccionar los pliegos y llamar a licitación pública. También deben inspeccionar las obras, certificar el avance físico, administrar los recursos y resolver el sistema de selección de los beneficiarios. Paralelamente, el gobierno

\footnotetext{
5 Monto que fue otorgado para el período 2004 - 2006.
} 
nacional selecciona, financia y audita los proyectos presentados por los municipios; los Institutos Provinciales de Vivienda supervisan el avance de las obras, orientan y fiscalizan el proceso de adjudicación, escrituran las viviendas y recuperan la inversión. De todas maneras, el nuevo rol de los gobiernos locales, sumado a la ausencia de manuales, instructivos y talleres de capacitaciones, generó una gran diversidad en el modo de implementación y ejecución del proyecto en cada municipio. Frente a la necesidad de resolver estas cuestiones y con el fin de aplicar en sus jurisdicciones el Plan Federal, cada municipio procedió a la creación de diversas instancias, secretarías y subsecretarías, configurando así diversos estilos y procedimientos de actuación.

A su vez, cada uno de estos programas se organizó a través de distintos subprogramas. En el año 2005, se anuncia el lanzamiento del Subprograma Federal de Urbanización de Villas y Asentamientos Precarios. El cual, concentrado inicialmente sólo en el AMBA, se incorporó como un subproducto de las operatorias de Construcción y Mejoramiento de Viviendas, disponiendo de parte de su financiamiento. Tal como señala BETTATIS (2012), la falta de suelo en donde concretar las obras incidió en el surgimiento de esta línea de acción, definiendo a las villas y a los asentamientos como espacios estratégicos, donde las acciones de re-urbanización podrían intervenir sobre la precariedad habitacional extrema y emplear los terrenos para localizar parte de las viviendas anunciadas. En consecuencia, el Subprograma Federal de Urbanización, además de diferenciarse del resto de los programas por enfocarse específicamente en los habitantes pertenecientes a villas y asentamientos, tiene objetivos integrales que superan tanto a una típica política de "llave en mano", como al énfasis constructivo del Programa Federal. Los mismos son: regularización dominial en favor de los ocupantes efectivos del territorio, obras de saneamiento básico, provisión de infraestructura y servicios básicos, consolidación de espacios públicos y relocalización de los hogares ubicados en sectores urbanos con riesgo ambiental.

Resulta indispensable resaltar la existencia de actores privados, protagonistas de la ejecución de estos proyectos. Por un lado, se encuentra el sector vinculado a la industria de la construcción, es decir, las empresas constructoras y aquellas vinculadas a los rubros que producen insumos para la construcción (ello es: materias primas y productos de escasa elaboración como cemento, hierro, arena, etcétera). Por otro lado, se ubican los propietarios de tierra urbana o de tierra urbanizable, cuyos predios, ante el lanzamiento del programa, se vieron en creciente demanda, posibilitando el surgimiento de una lógica eminentemente especulativa. En este sentido, es necesario destacar la ausencia de financiamiento de suelo urbano en los Planes Federales, es decir, no obstante de la falta de financiamiento para su obtención, no existe una política clara en los Convenios Marco acerca de las tierras a utilizar para la construcción de viviendas. Por lo cual, consideramos que existe una disociación entre la relación de la provisión de la vivienda y la de su soporte. 


\section{Los Planes Federales en el Conurbano Bonaerense}

La implementación de los Programas Federales, al mismo tiempo que implicó una reformulación de la política habitacional nacional, intervino y modificó el escenario de distribución de las viviendas en el AMBA. Según el INDEC (INSTITUTO NACIONAL DE ESTADÍSTICAS Y CENSOS), el AMBA está compuesto por la ciudad central (Ciudad Autónoma de Buenos Aires $)^{6}$ y los 24 municipios de la provincia de Buenos Aires que conforman el Conurbano Bonaerense. Ellos son: Lomas de Zamora, Quilmes, Lanús, General San Martín, Tres de Febrero, Avellaneda, Morón, San Isidro, Malvinas Argentinas, Vicente López, San Miguel, José C. Paz, Hurlingham, Ituzaingó, La Matanza, Almirante Brown, Merlo, Moreno, Florencio Varela, Tigre, Berazategui, Esteban Echeverría, San Fernando y Ezeiza. En este artículo, centraremos nuestra atención en los 24 municipios, en el Conurbano Bonaerense.

En lo que respecta a la implementación de estos Programas, a comienzos del 2014, tras diez años del lanzamiento, se habían ejecutado -o se encuentran aún en ejecución- 28.527 viviendas nuevas (en localizaciones también nuevas), a través del PFCV; 21.155 viviendas nuevas (en tierras ocupadas por villas y asentamientos precarios) a partir del Programa Federal de Urbanización de Villas y Asentamientos (PFUVyA) y 4.359 viviendas gracias al Programa Federal de Emergencia Habitacional (PFEH). En cuanto a las obras de mejoramientos, ello implica, obras que consisten en la terminación, ampliación y refacción de la vivienda de grupos familiares que necesiten que su actual residencia sea completada y/o mejorada; en el Conurbano Bonaerense, con la ejecución del Programa Federal Mejor Vivir (PFMV) se llevaron o se llevan a cabo actualmente, 20.207 mejoramientos $y$, en el marco del PFUVyA, 4.455 obras de esa tipología.

${ }^{6}$ Entre los objetivos del presente artículo no está analizar la implementación de los Programas Federales en la Ciudad Autónoma de Buenos Aires (CABA), sin embargo es posible mencionar algunas características de dicho proceso. En principio, puede advertirse que en la ciudad capital únicamente se implementaron el PFCV, el PFMV y el PUVyA, ya que el PFEH no fue afrontado. De este modo, el PFCV puso en marcha 3303 viviendas nuevas y 1 obra de infraestructura, el PFMV 3.329 mejoramientos, y el PUVyA 1.436 viviendas nuevas, 235 mejoramientos y 2 obras de infraestructura. En tanto, es preciso mencionar que entre las obras mencionadas, únicamente 307 viviendas y 171 mejoramientos habían comenzado a ejecutar las obras. Ante la amplia brecha que se observa al comparar las obras asignadas con las obras ejecutadas en Capital Federal, y el lento estado de avance de las soluciones habitacionales, es posible interrogarse por posibles dificultades que intervinieron en el escenario porteño. En este sentido, Fernando Ostuni (2010) resalta las limitaciones que impuso el cuerpo normativo de la Ciudad -que se destaca por tener, en comparación con otras jurisdicciones, un grado considerable de detalles y requisitos para la construcción de viviendas- ; las dificultades que existieron en el IVC para articular los Programas Federales con las problemáticas de los ámbitos donde el déficit habitacional se hacía más tangible: las villas; y, al tratarse la ciudad porteña de una Megalópolis, la agudización de un problema estructural de la política habitacional, a saber: la ausencia de suelo y/o de financiamiento para el mismo. Para un análisis detallado de su implementación, véase:"Políticas nacionales y escenarios locales. Reflexiones sobre la implementación del PFCV en CABA" (OSTUNI, 2010). 
Otra modalidad que adquiere importancia en el marco de la implementación de estos programas es la ejecución de obras de infraestructura pública que contribuyen al saneamiento de los barrios que son beneficiarios de los mismos. En este sentido, 317 obras de infraestructura fueron ejecutadas a partir del PFCV, del PFEH y PFUVyA. Es decir, en el Conurbano Bonaerense, se observa la ejecución de 78.703 soluciones habitacionales, a las que se le incorporan 317 obras de saneamiento básico, provisión de infraestructura y de servicios públicos ${ }^{7}$.

\begin{tabular}{|c|c|c|c|}
\hline \multirow{2}{*}{ Programa } & \multicolumn{2}{|c|}{ Soluciones Habitacionales } & \multirow{2}{*}{ Total } \\
\cline { 2 - 4 } & Viviendas & Mejoramientos & \\
\hline PFCV & $52,79 \%$ & $0,00 \%$ & $36,25 \%$ \\
& $(28.527)$ & $(0)$ & $(28.527)$ \\
\hline PFMV & $0,00 \%$ & $81,93 \%$ & $25,68 \%$ \\
& $(0)$ & $(20.207)$ & $(20.207)$ \\
\hline PFEH & $8,07 \%$ & $0,00 \%$ & $5,54 \%$ \\
& $(4.359)$ & $(0)$ & $(4.359)$ \\
\hline PFUVyA & $39,15 \%$ & $18,06 \%$ & $32,54 \%$ \\
& $(21.155)$ & $(4.455)$ & $(25.610)$ \\
\hline Total & $100,00 \%$ & $100,00 \%$ & $100,00 \%$ \\
& $(54.041)$ & $(24.662)$ & $(78.703)$ \\
\hline
\end{tabular}

Cuadro 1 - Soluciones habitacionales según tipología y Programa Federal (en porcentajes y absolutos). Conurbano Bonaerense, $2014^{8}$.

Fuente: Elaboración propia a partir de datos de la Subsecretaría de Desarrollo Urbano y Vivienda (SSDUyV), 2014.

\begin{tabular}{|c|c|}
\hline Programa & Obras de Infraestructura \\
\hline PFCV & $42,90 \%$ \\
\hline
\end{tabular}

7 Se consignan aquellos que en la base de datos presentada por la Subsecretaría de Desarrollo Urbano y Vivienda (SSDUyV) informen "Estado de Avance" y "Localización". Debido a la falta de dicha información y por rigurosidad metodológica, entre los cuatro Programas, se han dejado de lado 983 casos, de los cuales: 744 corresponden a vivienda, 233 a mejoramientos y 6 a infraestructura.

8 Se consignan las obras en ejecución y las terminadas. 


\begin{tabular}{|c|c|}
\hline & $(136)$ \\
\hline PFMV & $0,00 \%$ \\
& $(0)$ \\
\hline PFEH & $17,35 \%$ \\
& $(55)$ \\
\hline PFUVyA & $39,75 \%$ \\
\hline Total & $(126)$ \\
\hline & $100,00 \%$ \\
\hline
\end{tabular}

Cuadro 2 - Obras de infraestructura según Programa Federal (en porcentajes y absolutos). Conurbano Bonaerense, 2014.

Fuente: Elaboración propia a partir de datos de la Subsecretaría de Desarrollo Urbano y Vivienda (SSDUyV), 2014.

A partir de observar los Cuadros 1 y 2 , en lo que respecta a soluciones habitacionales la distribución por Programa es similar entre el PFCV, el PFMV y el PFUVyA. Sin embargo, lo contrario sucede con el PFEH, ya que sólo contribuye en un 5,54\% sobre el total de soluciones habitacionales, mientras que el resto lo hace entre un $25 \%$ y un $36 \%$. En cuanto a las obras de Infraestructura, el aporte principal lo hacen el PFCV y el PFUVyA, con valores equivalentes, mientras que en menor medida contribuye el PFEH. Es posible observar que el PFEH participa en un porcentaje pequeño en la provisión de infraestructura y aún menor en la ejecución de soluciones habitacionales totales implementadas en el AMBA; detalle que no es menor, dado que es el único programa que incorpora exclusivamente a organizaciones sociales en su implementación.

Estos datos adquieren relevancia al tomarse en cuenta la situación habitacional en la que se encuentra actualmente el Conurbano Bonaerense. A partir de datos del último Censo (2010), observamos que en el Conurbano Bonaerense se empadronaron 2.934.373 hogares. Lo que refleja un aumento de un 23,04\%, es decir, de 549.425 hogares respecto al Censo del año 2001 (en donde se habían registrado 2.384.948 familias). Sin embargo, de ese total, el 30,67\% (899.914) conviven con situaciones deficitarias ${ }^{9}$. Y, dentro de este grupo -tal como señaláramos

${ }^{9}$ Al mencionar situaciones deficitarias nos referimos a hogares que se encuentran en situación de hacinamiento o que habitan viviendas identificadas por el INDEC como: Casa tipo B, Pieza/s en inquilinato, 
en trabajos anteriores (Véase DI VIRGILIO; RODRÍGUEZ; MERA, 2016)-, el 49,9\% (448.985) de los hogares requieren mejorar su locación actual; el 37,34\% (336.084) padecen hacinamiento en viviendas no precarias pero necesitan también de una nueva vivienda $y$, finalmente, el $12,76 \%(114.845)$ requieren de una nueva vivienda.

Por lo tanto, al poner en diálogo estos valores con las soluciones habitacionales que los Programas Federales impulsan en el Conurbano observamos que, mientras 899.914 hogares conviven con situaciones deficitarias de vivienda, el conjunto de Planes Federales aplicados en este territorio solamente proporcionan 78.703 soluciones habitacionales, lo que alcanzaría únicamente para paliar las necesidades del $8,75 \%$ de los hogares que residen en viviendas con estas características. A su vez, es posible observar que en su ejecución, los Programas, priorizan la construcción de viviendas nuevas por sobre la implementación de mejoramientos; sin embargo, como mencionamos previamente, en el Censo 2010 es posible detectar que entre los hogares que se encuentran en situación deficitaria, el porcentaje que precisa vivienda nueva es significativamente menor que aquellos que requieren mejorar su locación.

Esta situación se complejiza aún más cuando se observa la situación por vivienda. Es decir, en el año 2010, se registraron 2.998.867 viviendas en el Conurbano Bonaerense. Lo que, respecto al Censo del 2001, muestra un incremento de un 24,22\% (726.308 viviendas). Sin embargo, del total de viviendas empadronadas al 2010, el 11,47\% corresponden a viviendas particulares deshabitadas (344.006 viviendas) presentando los municipios de La Matanza, Lanús y Lomas de Zamora, valores superiores a 20.000 viviendas con estas características. Por lo cual, si lo vinculamos con la cantidad de hogares nuevos que presionan sobre el stock de viviendas disponibles es posible observar que el stock de viviendas deshabitadas podría llegar a cubrir las necesidades habitacionales de más del $50 \%$ de estos nuevos hogares. El resto comprende a viviendas particulares habitadas, lo que implica un $88,47 \%$ (2.653.288 viviendas) y viviendas colectivas, representando a un $0,06 \%$ del total, es decir, 1.573 viviendas.

Como señalamos en la sección anterior, los Programas Federales privilegiaron a los gobiernos locales para la construcción masiva de viviendas y su escala les ofreció una gran posibilidad de acceso a nuevos recursos para las obras, pero al mismo tiempo, situó a los municipios frente al desafío de proveerse de suelo urbano. En este sentido la dificultad era múltiple, debido a que: i) existía una escasez relativa de lotes y predios amanzanados disponibles y aptos para la construcción en el AMBA (CLICHEVSKY, 1999; OSTUNI, 2007); ii) los municipios tenían exigua experiencia técnica en política de gestión de suelo; iii) los programas estaban pensados para su inmediata implementación lo que obligaba a los municipios y a la

Rancho, Casilla, Local no construido para habitación, Vivienda móvil, Pieza/s en hotel o pensión (Las casas tipo $B$ se consideran todas aquellas que cumplen por lo menos con una de las siguientes condiciones: tienen piso de tierra o ladrillo suelto u otro material (no tienen piso de cerámica, baldosa, mosaico, mármol, madera o alfombrado, cemento o ladrillo fijo) o no tienen provisión de agua por cañería dentro de la vivienda o no disponen de inodoro con descarga de agua). 
provincia a contar con suelo disponible, en el menor tiempo posible, para no perder los cupos obtenidos (DEL RÍO; DUARTE, 2012) ${ }^{10}$. Al parecer, esta compleja realidad no fue contemplada en el lanzamiento de los programas, ya que se buscaba utilizar para las soluciones habitacionales, suelo fiscal de domino municipal y provincial. En este contexto, la ejecución de los programas provocó el alza del precio del suelo y de las expectativas de los propietarios de la tierra rural o cuasi-urbana, que esperaban transformar su suelo en suelo urbano por medio de los Programas Federales (DEL RÍO; DUARTE, 2012).

En pos de solucionar esta dificultad, el Estado Provincial diseñó la modalidad "Tierra y Proyecto Urbano (TPU)" para la provincia de Buenos Aires. De este modo, se convocó a licitaciones en las cuales las empresas constructoras debieron presentar proyectos integrales en los que estuviera incluido, además del proyecto de construcción de las viviendas, el suelo donde se edificaría y el proyecto urbano para el barrio en cuestión. El Instituto de Vivienda de la Provincia de Buenos Aires aportaba hasta el $11 \%$ del precio de la vivienda, cuya superficie mínima financiaba el Estado Nacional y las empresas constructoras debían obtener y proponer terrenos para la implementación de los Programas en el AMBA ${ }^{11}$.

La implementación del PFUVyA también permitió destrabar esta problemática. Al estar diseñado para ejecutarse en villas y asentamientos, su implementación se hizo ya no en tierras baldías, sino en tierras ocupadas y, únicamente, en suelos aledaños cuando se precisó relocalizar viviendas para regularizar la trama urbana y adaptar el proyecto a la normativa vigente. A ello se le incorporó que uno de los requerimientos para su ejecución era que se hiciera en suelo regularizado en términos dominiales o en proceso de regularización, generando así que la Escribanía General del Gobierno de la Provincia tuviera que desplegar una acción masiva de regularización, lo que provocó la incorporación de barrios que hacía décadas que estaban en situaciones dominiales precarias e informales. Es decir, la implementación de este subprograma es doblemente interesante ya que, por un lado, posibilita que los gobiernos locales dispongan de suelo urbano para implementar el PFCV y, a su vez, estimula que el Estado Nacional y Provincial actúe en tierras ya elegidas, en barrios ya creados y auto-urbanizados por los sectores populares.

Veamos, entonces, el escenario descripto a partir de la implementación de los programas a lo largo del tiempo. Si comparamos las obras ejecutadas, que respectan a la construcción de viviendas nuevas, entre el lanzamiento de los Federales y el año 2009 y las obras ejecutadas entre el año 2010 y el 2014, observamos que: en esta segunda etapa, el PFEH

10 Según el Convenio Marco firmado entre el Estado y las provincias, las provincias tenían un plazo máximo de seis meses para comenzar la ejecución de los cupos asignados ya que, pasado ese plazo, los recursos iban a ser reasignados a otras provincias.

${ }^{11}$ Del Río y Duarte han estudiado la participación que tuvo la modalidad TPU en las viviendas construidas y la superficie adquirida; en este sentido, en el 2009 a partir de esta modalidad se habían construido el $52,1 \%$ de las viviendas ejecutadas por el Federal y se había adquirido el 50,5\% de la superficie de suelo (2012). 
logró poner en ejecución menos de una sexta parte $(14,58 \%)$ de las viviendas nuevas que había logrado poner en ejecución en la primera etapa (3.804 viviendas frente a 555 unidades del segundo período). Por otro lado, el PFCV pone en ejecución aproximadamente la mitad (53,78\%) de las viviendas nuevas que había logrado poner en ejecución en la primera etapa (18.551 nuevas viviendas frente a 9.976 unidades) y, finalmente, sólo el PFUVyA logró poner en ejecución casi idéntica cantidad de viviendas nuevas en el segundo período (93,37\%) del que había logrado en el primero (10.940 nuevas viviendas frente a 10.215 unidades). Es decir, tras los primeros años de lanzamiento, el único programa que logró continuar sostenidamente la puesta en marcha de obras de vivienda nueva fue el Subprograma de Urbanización de Villas y Asentamientos. Es posible poner en diálogo estos resultados con las dificultades, previamente mencionadas, a la que se enfrentó la Provincia y los municipios para obtener suelo urbano, limitación que pudo haber sido sorteada por los gobiernos locales mediante la elección de tierras en villas y asentamientos.

\begin{tabular}{|c|c|c|}
\hline \multirow{2}{*}{ Programa } & \multicolumn{2}{|c|}{ Viviendas nuevas ejecutadas } \\
\cline { 2 - 3 } & Período 2004-200912 & Período 2010-2014 \\
\hline PFEH & 3.804 & 555 \\
\hline PFCV & 18.551 & 9.976 \\
\hline PFUVyA & 10.940 & 10.215 \\
\hline Total & 33.295 & 20.746 \\
\hline
\end{tabular}

Cuadro 3 - Viviendas nuevas por Programa Federal, según período en el que fueron puestas en ejecución (en absolutos). Conurbano Bonaerense, 2014.

Fuente: Elaboración propia a partir de datos de la Subsecretaría de Desarrollo Urbano y Vivienda (SSDUyV), 2009 y 2014.

Asimismo, es posible observar cómo ha sido el avance de las soluciones habitacionales ejecutadas. Si nos focalizamos en las viviendas nuevas -ver Cuadro 4 - encontramos que, el $52,01 \%$ de las viviendas nuevas ejecutadas se encuentran terminadas mientras que, el $12,71 \%$ de las viviendas nuevas aún no han superado el $20 \%$ de avance en la obra. Si desagregamos lo expuesto observamos que, de las viviendas nuevas ejecutadas en el marco del PFCV, el 65,00\% se encuentran terminadas y únicamente el 7,39\% aún no han alcanzado el $20 \%$ de avance en la obra. Entre las ejecutadas en el marco del PFEH, el 86,95\% de las viviendas nuevas están

12 Se le asignará al período "2004-2009" en términos formales, sin embargo se tendrá en cuenta para el análisis que recién en julio de 2004 el Gobierno Nacional lanzó el Programa Federal de Mejoramiento de Viviendas y el Plan Federal de Construcción de Viviendas y en el 2005 presentó el Programa Federal de Urbanización de Villas y Asentamientos. 
terminadas; el $11,86 \%$ está en ejecución avanzada y sólo el $1,19 \%$ no ha alcanzado el $20 \%$ de avance en la obra. Sin embargo, el panorama se modifica cuando observamos las viviendas nuevas ejecutadas en el marco del PFUVyA, ya que encontramos que sólo el $27,30 \%$ de las unidades están terminadas mientras que, el 50,43\% se encuentra en ejecución y el $22,27 \%$ restante todavía no ha alcanzado el $20 \%$ de avance en la obra.

Al focalizarnos en los mejoramientos efectuados en viviendas existentes, es posible observar que el 63,40\% de los mejoramientos efectuados en el marco del PFMV y el PFUVyA se encuentra terminado, el 25,19\% de los mejoramientos se encuentra en ejecución avanzada y sólo el $11,41 \%$ no ha logrado alcanzar un $20 \%$ de avance en la obra. Al desagregar por programa se observan diferencias entre sí ya que, mientras que el PFUVyA tiene el 93,56\% de las obras terminadas, el PFMV sólo lo hace en un $56,75 \%$.

En el caso de las obras de infraestructura efectuadas en el AMBA -a partir del PFCV, el PFEH y el PFUVyA- se observa que el $64,04 \%$ se encuentran terminadas. Si desagregamos por programa, nos encontramos con que el porcentaje aumenta levemente en el caso del PFCV, debido a que el $68,38 \%$ de las obras se encuentran terminadas, y en el PFEH, ya que este valor alcanza al 70,91\%. Por el contrario, entre las obras de infraestructura implementadas a partir del PFUVyA, el porcentaje de aquellas que se encontraban terminadas, es decir un 56,35\%, registra un descenso; mientras que aumenta el porcentaje de las obras de infraestructura que al 2014 no habían alcanzado el 20\% de ejecución.

En tanto, para comprender los tiempos de avance que expresa la implementación del PFUVyA, es preciso tener en cuenta que los proyectos de urbanización contemplan mucho más que la construcción de viviendas o la ejecución de mejoramientos, ya que se trata de proyectos que necesitan liberar tierras que posibiliten la construcción de viviendas nuevas, la ejecución de obras de infraestructura y la concreción de la traza urbana; para ello, se precisa gestión y organización por parte de los gobiernos locales -y especialmente su equipo técnico- para generar espacios de trabajo comunitario donde se fortalezca el proyecto y se forje el consenso necesario para avanzar en la urbanización. Es posible que los pasos descriptos, y el esfuerzo que ello requiere en términos de gestión local, expliquen porque se opta por la construcción de vivienda nueva entre los municipios que poseen terrenos baldíos.

\begin{tabular}{|c|c|c|c|c|c|c|c|}
\hline \multirow{2}{*}{$\begin{array}{c}\text { Estado } \\
\text { de }\end{array}$} & \multicolumn{6}{|c|}{ Soluciones Habitacionales } \\
\cline { 2 - 7 } Avance & PFCV & PFEH & PFUVyA & $\begin{array}{c}\text { Todos los } \\
\text { programas }\end{array}$ & PFMV & PFUVyA & $\begin{array}{c}\text { Todos los } \\
\text { programas }\end{array}$ \\
\cline { 2 - 7 } & & & \multicolumn{4}{|c|}{ Viviendas } & Mejoramientos \\
\hline
\end{tabular}




\begin{tabular}{|c|c|c|c|c|c|c|c|}
$\begin{array}{c}\text { En } \\
\text { ejecución } \\
(\leq 20 \%)\end{array}$ & $\begin{array}{c}7,39 \% \\
(2.108)\end{array}$ & $\begin{array}{c}1,19 \% \\
(52)\end{array}$ & $\begin{array}{c}22,27 \% \\
(4.711)\end{array}$ & $\begin{array}{c}12,71 \% \\
(6.871)\end{array}$ & $\begin{array}{c}12,69 \% \\
(2.564)\end{array}$ & $\begin{array}{c}5,61 \% \\
(250)\end{array}$ & $\begin{array}{c}11,41 \% \\
(2.814)\end{array}$ \\
\hline $\begin{array}{c}\text { En } \\
\text { ejecución } \\
(>20 \%)\end{array}$ & $\begin{array}{c}27,61 \% \\
(7.876)\end{array}$ & $\begin{array}{c}11,86 \% \\
(517)\end{array}$ & $\begin{array}{c}50,43 \% \\
(10.668)\end{array}$ & $\begin{array}{c}35,27 \% \\
(19.061)\end{array}$ & $\begin{array}{c}30,56 \% \\
(6.175)\end{array}$ & $\begin{array}{c}0,83 \% \\
(37)\end{array}$ & $\begin{array}{c}25,19 \% \\
(6.212)\end{array}$ \\
\hline $\begin{array}{c}\text { Termina- } \\
\text { das }^{13}\end{array}$ & $\begin{array}{c}65,00 \% \\
(18.543)\end{array}$ & $\begin{array}{c}86,95 \% \\
(3.790)\end{array}$ & $\begin{array}{c}27,30 \% \\
(5.776)\end{array}$ & $\begin{array}{c}52,01 \% \\
(28.109)\end{array}$ & $\begin{array}{c}56,75 \% \\
(11.468)\end{array}$ & $\begin{array}{c}93,56 \% \\
(4.168)\end{array}$ & $\begin{array}{c}63,40 \% \\
(15.636)\end{array}$ \\
\hline Total & $100,00 \%$ & $100,00 \%$ & $100,00 \%$ & $100,00 \%$ & $100,00 \%$ & $100,00 \%$ & $100,00 \%$ \\
$(28.527)$ & $(4.359)$ & $(21.155)$ & $(54.041)$ & $(20.207)$ & $(4.455)$ & $(24.662)$ \\
\hline
\end{tabular}

Cuadro 4 - Soluciones habitacionales por tipología y Programa Federal según estado de avance de la obra (en porcentajes y absolutos). Conurbano Bonaerense, 2014.

Fuente: Elaboración propia a partir de datos de la Subsecretaría de Desarrollo Urbano y Vivienda (SSDUyV), 2014.

\begin{tabular}{|c|c|c|c|c|}
\hline \multirow{2}{*}{ Estado de Avance } & \multicolumn{4}{|c|}{ Obras de Infraestructura } \\
\cline { 2 - 5 } & PFCV & PFEH & PFUVyA & Todos los programas \\
\hline \multirow{2}{*}{ En ejecución $(\leq 20 \%)$} & $5,15 \%$ & $7,27 \%$ & $19,05 \%$ & $11,04 \%$ \\
& $(7)$ & $(4)$ & $(24)$ & $(35)$ \\
\hline \multirow{2}{*}{ En ejecución $(>20 \%)$} & $26,47 \%$ & $21,82 \%$ & $24,60 \%$ & $24,92 \%$ \\
& $(36)$ & $(12)$ & $(31)$ & $(79)$ \\
\hline \multirow{2}{*}{ Terminadas } & $68,38 \%$ & $70,91 \%$ & $56,35 \%$ & $64,04 \%$ \\
& $(93)$ & $(39)$ & $(71)$ & $(203)$ \\
\hline \multirow{2}{*}{ Total } & $100,00 \%$ & $100,00 \%$ & $100,00 \%$ & $100,00 \%$ \\
& $(136)$ & $(55)$ & $(126)$ & $(317)$ \\
\hline
\end{tabular}

Cuadro 5 - obras de infraestructura por Programa Federal según estado de avance de la obra (en porcentajes y absolutos). Conurbano Bonaerense, 2014.

Fuente: Elaboración propia a partir de datos de la Subsecretaría de Desarrollo Urbano y Vivienda (SSDUyV), 2014. $98 \%$ o más.

${ }^{13}$ Se consignan como "Terminadas" aquellas obras que al 2014 hayan alcanzado un avance del 
Finalmente, al focalizarnos en la localización de las soluciones habitacionales (Cuadro 6) se observa que el $46,33 \%$ de las mismas se encuentran ubicadas en la primera corona, es decir, entre Avellaneda, San Martín, La Matanza, Lanús, Lomas de Zamora, Morón, San Isidro, Tres de Febrero y Vicente López; y el 53,67\% en la segunda corona, esto es, entre Almirante Brown, Berazategui, Esteban Echeverria, Ezeiza, Florencia Varela, Hurlingham, Ituzaingó, Jospé C. Paza, Malvinas Argentinas, Merlo, Moreno, Quilmes, San Fernando, San Miguel y Tigre. Sin embargo, al profundizar el análisis y desagregar las viviendas y los mejoramientos, nos encontramos con que mientras el $58,78 \%$ de las viviendas construidas a nuevo se ubican en la segunda corona, el $57,53 \%$ de los mejoramientos se realizaron en viviendas ubicadas en la primera corona. Es decir, es posible observar que los mejoramientos se priorizan en el primero cordón, mientras la construcción de vivienda nueva predomina en el segundo.

Paralelamente, al desagregar por los Planes Federales, se observa que la distribución de la soluciones habitacionales en el Conurbano no se expresa igualmente al interior de los diversos programas. A modo de ejemplo, de las 21.155 viviendas que se construyeron a partir del PFUVYA, el 69,42\% de ellas se localizan en la primera corona, al igual que el 96,64\% de los 4.305 mejoramientos realizados a partir de este programa. Lo contrario sucede en la implementación del PFCV, ya que de las 28.527 viviendas nuevas en ejecución, únicamente el $23,35 \%$ se localizan en la primera corona. Asimismo, entre las 4.359 viviendas en ejecución a partir del PFEH, sólo el $21,33 \%$ se ubica en la primera corona. Sin embargo, en el caso de los mejoramientos implementados a partir del PFUVyA, el 96,64\% se localizó en la primera corona, al igual que el $48,91 \%$ de los implementados por el PFMV.

De este modo, se observa que conforme nos alejamos de la ciudad central, la opción por proyectos habitacionales que priorizan la urbanización de villas o asentamientos disminuye profundamente. Es decir, mientras en la primera corona, ante la falta de suelo urbano, el PFUVyA permitió destrabar la problemática, poniendo como sujeto del programa a las tierras ocupadas por villas o asentamientos; en la segunda corona, frente a la mayor disponibilidad de parcelas libres para la implementación de proyectos nuevos, los gobiernos locales parecieran haber dejado de lado la generación de alternativas de urbanización y planificación sobre el territorio, que posibilitasen resolver los problemas habitacionales vigentes en su territorio, para optar mayoritariamente por la construcción de viviendas nuevas.

\begin{tabular}{|l|c|c|c|c|c|}
\hline \multirow{2}{*}{$\begin{array}{l}\text { Locali- } \\
\text { zación }\end{array}$} & Viviendas & $\begin{array}{c}\text { Total } \\
\text { Vivien- } \\
\text { das }\end{array}$ & Mejoramientos & $\begin{array}{c}\text { Total } \\
\text { mejora- } \\
\text { mientos }\end{array}$ & $\begin{array}{c}\text { Total de } \\
\text { solucio- } \\
\text { nes }\end{array}$ \\
\cline { 2 - 5 }
\end{tabular}




\begin{tabular}{|c|c|c|c|c|c|c|c|c|}
\hline & $\underset{u}{\longrightarrow}$ & $\begin{array}{l}\frac{I}{u} \\
\frac{u}{Q}\end{array}$ & $\sum_{\frac{11}{2}}^{\frac{\pi}{2}}$ & & $\sum_{\frac{u}{\alpha}}^{\geq}$ & $\sum_{\frac{1}{2}}^{\frac{\pi}{2}}$ & & $\begin{array}{l}\text { habita- } \\
\text { cionales }\end{array}$ \\
\hline $\begin{array}{c}\text { Total } \\
\text { Primera } \\
\text { Corona }\end{array}$ & $\begin{array}{l}23,35 \% \\
(6.661)\end{array}$ & $\begin{array}{c}21,33 \% \\
(930)\end{array}$ & $\begin{array}{c}69,42 \% \\
(14.686)\end{array}$ & $\begin{array}{c}41,22 \% \\
(22.277)\end{array}$ & $\begin{array}{l}48,91 \% \\
(9.882)\end{array}$ & $\begin{array}{l}96,64 \% \\
(4.305)\end{array}$ & $\begin{array}{c}57,53 \% \\
(14.187)\end{array}$ & $\begin{array}{c}46,33 \% \\
(36.464)\end{array}$ \\
\hline $\begin{array}{l}\text { Total } \\
\text { Segun- } \\
\text { da } \\
\text { Corona }\end{array}$ & $\begin{array}{c}76,65 \% \\
(21.866)\end{array}$ & $\begin{array}{l}78,66 \% \\
(3.429)\end{array}$ & $\begin{array}{l}30,58 \% \\
(6.469)\end{array}$ & $\begin{array}{c}58,78 \% \\
(31.764)\end{array}$ & $\begin{array}{c}51,09 \% \\
(10.325)\end{array}$ & $\begin{array}{c}3,37 \% \\
(150)\end{array}$ & $\begin{array}{c}42,47 \% \\
(10.475)\end{array}$ & $\begin{array}{c}53,67 \% \\
(42.239)\end{array}$ \\
\hline Total & $\begin{array}{c}100 \% \\
(28.527)\end{array}$ & $\begin{array}{c}100 \% \\
(4.359)\end{array}$ & $\begin{array}{c}100 \% \\
(21.155)\end{array}$ & $\begin{array}{c}100 \% \\
(54.041)\end{array}$ & $\begin{array}{c}100 \% \\
(20.207)\end{array}$ & $\begin{array}{c}100 \% \\
(4.455)\end{array}$ & $\begin{array}{c}100 \% \\
(24.662)\end{array}$ & $\begin{array}{c}100 \% \\
(78.703)\end{array}$ \\
\hline
\end{tabular}

Cuadro 6 - Soluciones habitacionales por tipología y Programa Federal según corona en la que se ubica la solución (en valores absolutos y relativos). Conurbano Bonaerense, 2014.

Fuente: Elaboración propia a partir de datos de la Subsecretaria de Desarrollo Urbano y Vivienda (SSDUyV), 2014

En el caso de las obras de infraestructura (Cuadro 7), de las 136 obras ejecutadas a partir del PFCV el $66,18 \%$ se ubica en la segunda corona, mientras menos de un tercio lo hace en la primera. Así también como el $58,20 \%$ de las 55 obras implementadas a partir del PFEH. Inversamente, de las 126 obras de infraestructura implementadas mediante el PFUVyA en el Conurbano, el $72,20 \%$ se ubica en la primera corona.

\begin{tabular}{|c|c|c|c|c|}
\hline \multirow[b]{2}{*}{ Localización } & \multicolumn{3}{|c|}{ Obras de infraestructura } & \multirow{2}{*}{$\begin{array}{c}\text { Total de } \\
\text { obras }\end{array}$} \\
\hline & PFCV & PFEH & PFUVyA & \\
\hline Primera Corona & $\begin{array}{c}33,82 \% \\
(46)\end{array}$ & $\begin{array}{l}41,80 \% \\
(23)\end{array}$ & $\begin{array}{c}72,2 \% \\
(91)\end{array}$ & $\begin{array}{c}50,47 \% \\
(160)\end{array}$ \\
\hline $\begin{array}{l}\text { Segunda } \\
\text { Corona }\end{array}$ & $\begin{array}{c}66,18 \% \\
(90)\end{array}$ & $\begin{array}{c}58,20 \% \\
(32)\end{array}$ & $\begin{array}{c}27,8 \% \\
(35)\end{array}$ & $\begin{array}{c}49,53 \% \\
(157)\end{array}$ \\
\hline Total & $\begin{array}{l}100 \% \\
(136)\end{array}$ & $\begin{array}{c}100 \% \\
(55)\end{array}$ & $\begin{array}{l}100 \% \\
(126)\end{array}$ & $\begin{array}{l}100 \% \\
(317)\end{array}$ \\
\hline
\end{tabular}

Cuadro 7 - Obras de Infraestructura por Programa Federal según corona en la que se ubica la obra (en porcentajes y absolutos). Conurbano Bonaerense, 2014.

Fuente: Elaboración propia a partir de datos de la Subsecretaria de Desarrollo Urbano y Vivienda (SSDUyV), 2014.

\section{La implementación de los Planes Federales en los municipios del Conurbano Bonaerense}


La implementación de los Programas Federales, con los gobiernos locales como actores centrales, implicaron una transformación en el formato histórico de intervención del gobierno nacional en los territorios municipales, debido a que los Institutos Provinciales dejaron en manos de los municipios los proyectos de intervención urbana, la gestión de su financiamiento, la confección de los pliegos, la inspección y certificación del avance físico de las obras y la elección del modo de selección de los beneficiarios. De esta forma, los Programas Federales, aún en un contexto de recentralización de la política habitacional post-crisis, transfirieron a los gobiernos provinciales y/o municipales las decisiones y el proceso de implementación de las obras. Hasta el momento, los municipios contaban con escasos recursos económicos para la definición y ejecución de políticas públicas propias. De este modo, frente al lanzamiento de estos programas, los municipios estuvieron en condiciones diferenciales al momento de acaparar y ejecutar los primeros cupos. Es decir, aquellos que conocían los procesos urbanos acaecidos en el territorio a partir de la disponibilidad de diagnósticos, aquellos que contaban con suelo o tenían experiencia en políticas de recuperación de suelo y quienes tenían ejercicio en la implementación de políticas habitacionales y/o poseían un equipo técnico constituido, se encontraban en una situación favorable en los inicios del programa frente a quienes no poseían esta experiencia (VARELA; FERNÁNDEZ WAGNER, 2012). Tal como se observa en el Cuadro 5, resultan evidentes las disparidades entre municipios en cuanto a la cantidad de soluciones habitacionales implementadas -construcción de viviendas y realización de obras de mejoramientos. De todas maneras, con el correr de la implementación esta situación fue equilibrándose.

En este sentido, entre los municipios que pusieron en marcha la mayor cantidad de soluciones habitacionales encontramos a: La Matanza; Moreno; José C. Paz; San Isidro y Florencio Varela; dichos municipios abarcan el $65,23 \%$ de las soluciones habitacionales implementadas en el Conurbano. Por el contrario, los municipios con menos soluciones habitacionales implementadas son: Ituzaingó; San Miguel; General San Martín; Lanús; Malvinas Argentinas y, finalmente, Vicente López que no llegan a representar el 5\% de la totalidad.

Al observar cada uno de los Programas y desagregarlos por tipo de soluciones habitacionales, en lo que respecta a viviendas ejecutadas a partir de PFCV, el $50 \%$ del total implementado en el Conurbano le corresponde a tres de los veinticuatro municipios del AMBA (ver Cuadro 8), ellos son: José C. Paz (18,63\%), Florencio Varela (15,91\%) y La Matanza $(13,37 \%)$. De todos modos, esta concentración puede deberse a la falta de tierras disponibles para la construcción en el resto de los municipios del Conurbano, especialmente en aquellos que constituyen la primera corona de la conurbación. Otro Programa que también se encarga de la construcción de viviendas es el PFEH, si bien en el Conurbano no tiene mucha incidencia ya que solamente hasta el momento se ha ejecutado en siete municipios, el 39,09\% del total de la ejecución corresponde a las llevadas a cabo por el partido de José C. Paz. Por último, en lo que respecta al PFUVyA, aquí la implementación tiene mayor incidencia en los municipios de 
Avellaneda, San Isidro, Quilmes y Tres de Febrero; los cuatro municipios abarcan el 55,39\% del total de las viviendas implementadas por este Programa.

En lo que comprende a los mejoramientos, aquí encontramos dos Programas Federales: el Mejor Vivir y el de Urbanización de Villas y Asentamientos. En cuanto al primero de ellos, a pesar de que se implementa en 18 de los 24 municipios, aproximadamente el $60 \%$ de su participación se la debe a Moreno, La Matanza y Avellaneda, cada uno con: 5.903, 3.372 y 3.200 mejoramientos respectivamente. Asimismo, el PFUVyA, el cual representa únicamente una quinta parte del PFMV, incide en los municipios de San Isidro, Lomas de Zamora, Quilmes, Avellaneda y Morón, superando ampliamente su participación en el municipio de San Isidro.

\begin{tabular}{|c|c|c|c|c|c|c|c|c|c|c|c|c|c|}
\hline \multirow{3}{*}{$\frac{\text { 을 }}{\frac{2}{0}}$} & \multicolumn{12}{|c|}{ Soluciones habitacionales } & \multirow{3}{*}{ 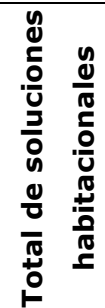 } \\
\hline & \multicolumn{6}{|c|}{ Viviendas } & \multirow[b]{2}{*}{$\begin{array}{c}\text { Total } \\
\text { vivien- } \\
\text { das }\end{array}$} & \multicolumn{4}{|c|}{ Mejoramientos } & \multirow{2}{*}{$\begin{array}{c}\text { Total } \\
\text { mejora } \\
- \\
\text { miento } \\
\text { s }\end{array}$} & \\
\hline & $\underset{u}{\longrightarrow}$ & $\begin{array}{l}\text { 己 } \\
\frac{1}{2} \\
0 ? \\
0\end{array}$ & $\frac{T}{\frac{I}{u}}$ & $\begin{array}{l}\frac{1}{4} \\
\frac{11}{0} \\
\circ \\
0\end{array}$ & $\frac{\nwarrow}{3}$ & $\begin{array}{l}\nwarrow \\
⿱ 亠 乂 \\
\frac{11}{2} \\
0 \\
0\end{array}$ & & $\sum_{\frac{L}{Q}}^{Z}$ & $\begin{array}{l}\sum_{\frac{1}{n}}^{Z} \\
0 \\
0\end{array}$ & 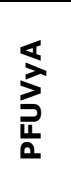 & $\begin{array}{l}\frac{\nwarrow}{3} \\
3 \\
\frac{11}{2} \\
\frac{0}{0}\end{array}$ & & \\
\hline 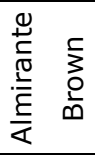 & 792 & $\begin{array}{c}2,78 \\
\%\end{array}$ & 0 & $\begin{array}{c}0,00 \\
\%\end{array}$ & 1.111 & $\begin{array}{c}5,25 \\
\%\end{array}$ & 1.903 & 117 & $0,58 \%$ & 0 & $\begin{array}{c}0,00 \\
\%\end{array}$ & 117 & 2.020 \\
\hline $\begin{array}{l}\frac{\pi}{0} \\
\stackrel{d}{C} \\
\frac{\pi}{0} \\
\overline{\bar{D}} \\
⿱ 亠 乂\end{array}$ & 1.583 & $\begin{array}{c}5,55 \\
\%\end{array}$ & 0 & $\begin{array}{c}0,00 \\
\%\end{array}$ & 3.763 & $\begin{array}{c}17,7 \\
9 \%\end{array}$ & 5.346 & 3.200 & $\begin{array}{c}15,84 \\
\%\end{array}$ & 150 & $\begin{array}{c}3,37 \\
\%\end{array}$ & 3.350 & 8.696 \\
\hline $\begin{array}{l}\bar{J} \\
\mathbb{D} \\
\mathbb{N} \\
\mathbb{N} \\
\mathbb{0} \\
\mathbb{0} \\
\infty\end{array}$ & 1.254 & $\begin{array}{c}4,40 \\
\%\end{array}$ & 0 & $\begin{array}{c}0,00 \\
\%\end{array}$ & 0 & $\begin{array}{c}0,00 \\
\%\end{array}$ & 1.254 & 0 & $0,00 \%$ & 0 & $\begin{array}{c}0,00 \\
\%\end{array}$ & 0 & 1.254 \\
\hline 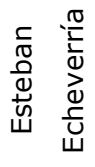 & 2.252 & $\begin{array}{c}7,89 \\
\%\end{array}$ & 0 & $\begin{array}{c}0,00 \\
\%\end{array}$ & 240 & $\begin{array}{c}1,13 \\
\%\end{array}$ & 2.492 & 0 & $0,00 \%$ & 0 & $\begin{array}{c}0,00 \\
\%\end{array}$ & 0 & 2.492 \\
\hline $\begin{array}{l}\mathbb{N} \\
\stackrel{N}{N} \\
\text { W }\end{array}$ & 1.074 & $\begin{array}{c}3,76 \\
\%\end{array}$ & 0 & $\begin{array}{c}0,00 \\
\%\end{array}$ & 216 & $\begin{array}{c}1,02 \\
\%\end{array}$ & 1.290 & 0 & $0,00 \%$ & 0 & $\begin{array}{c}0,00 \\
\%\end{array}$ & 0 & 1.290 \\
\hline $\begin{array}{ll}\frac{O}{U} & \frac{\pi}{0} \\
\frac{C}{0} & \frac{1}{N} \\
\frac{1}{0} & > \\
\frac{0}{4} & >\end{array}$ & 4.540 & $\begin{array}{c}15,9 \\
1 \%\end{array}$ & 713 & $\begin{array}{c}16,3 \\
6 \%\end{array}$ & 29 & $\begin{array}{c}0,14 \\
\%\end{array}$ & 5.282 & 1.112 & $5,50 \%$ & 0 & $\begin{array}{c}0,00 \\
\%\end{array}$ & 1.112 & 6.394 \\
\hline 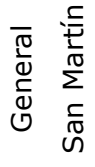 & 50 & $\begin{array}{c}0,18 \\
\%\end{array}$ & 0 & $\begin{array}{c}0,00 \\
\%\end{array}$ & 124 & $\begin{array}{c}0,59 \\
\%\end{array}$ & 174 & 20 & $0,10 \%$ & 0 & $\begin{array}{c}0,00 \\
\%\end{array}$ & 20 & 194 \\
\hline $\begin{array}{l}\frac{E}{1} \\
\frac{1}{D} \\
\frac{.}{5} \\
\frac{1}{5} \\
I\end{array}$ & 768 & $\begin{array}{c}2,69 \\
\%\end{array}$ & 0 & $\begin{array}{c}0,00 \\
\%\end{array}$ & 0 & $\begin{array}{c}0,00 \\
\%\end{array}$ & 768 & 161 & $0,80 \%$ & 0 & $\begin{array}{c}0,00 \\
\%\end{array}$ & 161 & 929 \\
\hline
\end{tabular}




\begin{tabular}{|c|c|c|c|c|c|c|c|c|c|c|c|c|c|}
\hline 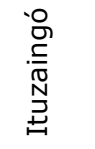 & 0 & $\begin{array}{c}0,00 \\
\%\end{array}$ & 0 & $\begin{array}{c}0,00 \\
\%\end{array}$ & 0 & $\begin{array}{c}0,00 \\
\%\end{array}$ & 0 & 76 & $0,38 \%$ & 0 & $\begin{array}{c}0,00 \\
\%\end{array}$ & 76 & 76 \\
\hline 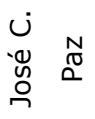 & 5.316 & $\begin{array}{c}18,6 \\
3 \%\end{array}$ & 1.704 & $\begin{array}{c}39,0 \\
9 \%\end{array}$ & 0 & $\begin{array}{c}0,00 \\
\%\end{array}$ & 7.020 & 1.617 & $8,00 \%$ & 0 & $\begin{array}{c}0,00 \\
\%\end{array}$ & 1.617 & 8.637 \\
\hline J & 3.814 & $\begin{array}{c}13,3 \\
7 \%\end{array}$ & 878 & $\begin{array}{c}20,1 \\
4 \%\end{array}$ & 1.925 & $\begin{array}{c}9,10 \\
\%\end{array}$ & 6.617 & 3.372 & $\begin{array}{c}16,69 \\
\%\end{array}$ & 0 & $\begin{array}{c}0,00 \\
\%\end{array}$ & 3.372 & 9.989 \\
\hline 氠 & 0 & $\begin{array}{c}0,00 \\
\%\end{array}$ & 0 & $\begin{array}{c}0,00 \\
\%\end{array}$ & 541 & $\begin{array}{c}2,56 \\
\%\end{array}$ & 541 & 38 & $0,19 \%$ & 0 & $\begin{array}{c}0,00 \\
\%\end{array}$ & 38 & 579 \\
\hline $\begin{array}{ll}0 & 0 \\
0 & \frac{0}{0} \\
0 & 0 \\
0 & \varepsilon \\
\varepsilon & \mathbb{0} \\
0 & N\end{array}$ & 152 & $\begin{array}{c}0,53 \\
\%\end{array}$ & 0 & $\begin{array}{c}0,00 \\
\%\end{array}$ & 1.689 & $\begin{array}{c}7,98 \\
\%\end{array}$ & 1.841 & 0 & $0,00 \%$ & 812 & $\begin{array}{c}18,2 \\
3 \%\end{array}$ & 812 & 2.653 \\
\hline 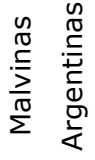 & 638 & $\begin{array}{c}2,24 \\
\%\end{array}$ & 0 & $\begin{array}{c}0,00 \\
\%\end{array}$ & 0 & $\begin{array}{c}0,00 \\
\%\end{array}$ & 638 & 0 & $0,00 \%$ & 0 & $\begin{array}{c}0,00 \\
\%\end{array}$ & 0 & 638 \\
\hline$\frac{\text { 은 }}{\frac{1}{2}}$ & 618 & $\begin{array}{c}2,17 \\
\%\end{array}$ & 0 & $\begin{array}{c}0,00 \\
\%\end{array}$ & 340 & $\begin{array}{c}1,61 \\
\%\end{array}$ & 958 & 243 & $1,20 \%$ & 0 & $\begin{array}{c}0,00 \\
\%\end{array}$ & 243 & 1.201 \\
\hline 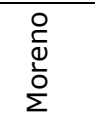 & 3.218 & $\begin{array}{c}11,2 \\
8 \%\end{array}$ & 600 & $\begin{array}{r}13,7 \\
6 \%\end{array}$ & 0 & $\begin{array}{c}0,00 \\
\%\end{array}$ & 3.818 & 5.903 & $\begin{array}{c}29,21 \\
\%\end{array}$ & 0 & $\begin{array}{c}0,00 \\
\%\end{array}$ & 5.903 & 9.721 \\
\hline 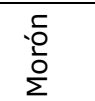 & 60 & $\begin{array}{c}0,21 \\
\%\end{array}$ & 0 & $\begin{array}{c}0,00 \\
\%\end{array}$ & 480 & $\begin{array}{c}2,27 \\
\%\end{array}$ & 540 & 796 & $3,94 \%$ & 37 & $\begin{array}{c}0,83 \\
\%\end{array}$ & 833 & 1.373 \\
\hline$\frac{\mathscr{\varrho}}{\stackrel{E}{\bar{O}}}$ & 415 & $\begin{array}{c}1,45 \\
\%\end{array}$ & 380 & $\begin{array}{c}8,72 \\
\%\end{array}$ & 2.651 & $\begin{array}{c}12,5 \\
3 \%\end{array}$ & 3.446 & 100 & $0,49 \%$ & 150 & $\begin{array}{c}3,37 \\
\%\end{array}$ & 250 & 3.696 \\
\hline 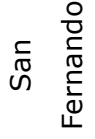 & 790 & $\begin{array}{c}2,77 \\
\%\end{array}$ & 32 & $\begin{array}{c}0,73 \\
\%\end{array}$ & 290 & $\begin{array}{c}1,37 \\
\%\end{array}$ & 1.112 & 472 & $2,34 \%$ & 0 & $\begin{array}{c}0,00 \\
\%\end{array}$ & 472 & 1.584 \\
\hline 돈 & 0 & $\begin{array}{c}0,00 \\
\%\end{array}$ & 0 & $\begin{array}{c}0,00 \\
\%\end{array}$ & 2.893 & $\begin{array}{c}13,6 \\
8 \%\end{array}$ & 2.893 & 1.700 & $8,41 \%$ & 3.306 & $\begin{array}{c}74,2 \\
1 \%\end{array}$ & 5.006 & 7.899 \\
\hline $\begin{array}{ll}\frac{\bar{d}}{J} \\
\stackrel{0}{\tilde{D}} \\
\stackrel{.0}{\Sigma}\end{array}$ & 160 & $\begin{array}{c}0,56 \\
\%\end{array}$ & 0 & $\begin{array}{c}0,00 \\
\%\end{array}$ & 0 & $\begin{array}{c}0,00 \\
\%\end{array}$ & 160 & 0 & $0,00 \%$ & 0 & $\begin{array}{c}0,00 \\
\%\end{array}$ & 0 & 160 \\
\hline 离 & 31 & $\begin{array}{c}0,11 \\
\%\end{array}$ & 0 & $\begin{array}{c}0,00 \\
\%\end{array}$ & 1.592 & $\begin{array}{c}7,53 \\
\%\end{array}$ & 1.623 & 524 & $2,59 \%$ & 0 & $\begin{array}{c}0,00 \\
\%\end{array}$ & 524 & 2.147 \\
\hline 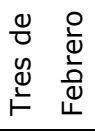 & 1.002 & $\begin{array}{c}3,51 \\
\%\end{array}$ & 52 & $\begin{array}{c}1,19 \\
\%\end{array}$ & 2.412 & $\begin{array}{c}11,4 \\
0 \%\end{array}$ & 3.466 & 740 & $3,66 \%$ & 0 & $\begin{array}{c}0,00 \\
\%\end{array}$ & 740 & 4.206 \\
\hline 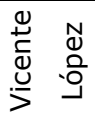 & 0 & $\begin{array}{c}0,00 \\
\%\end{array}$ & 0 & $\begin{array}{c}0,00 \\
\%\end{array}$ & 859 & $\begin{array}{c}4,06 \\
\%\end{array}$ & 859 & 16 & $0,08 \%$ & 0 & $\begin{array}{c}0,00 \\
\%\end{array}$ & 16 & 875 \\
\hline $\begin{array}{l}\bar{\pi} \\
\stackrel{0}{0} \\
\vdash\end{array}$ & 28.527 & $\begin{array}{l}100, \\
00 \%\end{array}$ & 4.359 & $\begin{array}{l}100, \\
00 \%\end{array}$ & 21.155 & $\begin{array}{l}100 \\
00 \%\end{array}$ & 54.041 & $\begin{array}{c}20.20 \\
7\end{array}$ & $\begin{array}{c}100,00 \\
\%\end{array}$ & 4.455 & $\begin{array}{l}100 \\
00 \%\end{array}$ & 24.662 & 78.703 \\
\hline
\end{tabular}


Cuadro 8 - Soluciones habitaciones por Programa Federal según municipio (en porcentajes y absolutos). Conurbano Bonaerense, 2014.

Fuente: Elaboración propia a partir de datos de la Subsecretaria de Desarrollo Urbano y Vivienda (SSDUyV), 2014.

Al poner en dialogo las soluciones habitacionales con las obras de infraestructura ejecutadas, es posible observar que las mismas están principalmente concentradas entre Avellaneda $(20 \%)$ y José C. Paz $(12,58 \%)$; municipios que también tuvieron una fuerte ejecución en materia de viviendas y mejoramientos. Paralelamente, La Matanza, Moreno y San Isidro -los otros tres municipios que más soluciones habitacionales implementaron- también llevaron a cabo obras de infraestructura, aunque lo hicieron en menor medida. De hecho, la sumatoria de las obras llevadas a cabo por estos tres municipios, no logran alcanzar a las implementadas por el municipio de Avellaneda.

Al mismo tiempo, es posible observar que Avellaneda $(30,16 \%)$, Quilmes $(15,08 \%)$ y San Isidro $(19,84 \%)$ concentran la mayor cantidad de las obras de infraestructura realizadas en el marco del PFUVyA. De todas formas, si se observa al interior del total de las obras ejecutadas por cada uno de estos municipios, es posible indicar que los tres priorizaron la ejecución de obras de infraestructura en Villas y Asentamientos.

En tanto, conforme nos alejamos de la ciudad central, la opción por proyectos habitacionales que priorizan la urbanización de villas o asentamientos se restringe, imponiéndose los grandes proyectos de vivienda nueva -en localizaciones nuevas- y combinándose con obras de infraestructura. Los municipios de José C. Paz, Ezeiza y Florencio Varela ejemplifican dicho fenómeno.

\begin{tabular}{|c|c|c|c|c|c|c|c|c|}
\hline \multirow{2}{*}{ Municipio } & \multicolumn{5}{|c|}{ Obras de Infraestructura } & \multicolumn{2}{c|}{$\begin{array}{c}\text { Total de } \\
\text { Obras }\end{array}$} \\
\cline { 2 - 10 } & PFCV & $\%$ PFCV & $\begin{array}{c}\text { PFE } \\
\text { H }\end{array}$ & $\%$ PFEH & $\begin{array}{c}\text { PFUVy } \\
\text { A }\end{array}$ & $\begin{array}{c}\text { \% } \\
\text { PFUVyA }\end{array}$ & N & $\%$ \\
\hline $\begin{array}{c}\text { Almirante } \\
\text { Brown }\end{array}$ & 2 & $1,55 \%$ & 0 & $0,00 \%$ & 3 & $2,38 \%$ & 5 & $1,61 \%$ \\
\hline Avellaneda & 18 & $13,95 \%$ & 6 & $10,91 \%$ & 38 & $30,16 \%$ & 62 & $20,00 \%$ \\
\hline Berazategui & 2 & $1,55 \%$ & 0 & $0,00 \%$ & 0 & $0,00 \%$ & 2 & $0,65 \%$ \\
\hline $\begin{array}{c}\text { Esteban } \\
\text { Echeverría }\end{array}$ & 14 & $10,85 \%$ & 1 & $1,82 \%$ & 1 & $0,79 \%$ & 16 & $5,16 \%$ \\
\hline Ezeiza & 6 & $4,65 \%$ & 1 & $1,82 \%$ & 3 & $2,38 \%$ & 10 & $3,23 \%$ \\
\hline
\end{tabular}




\begin{tabular}{|c|c|c|c|c|c|c|c|c|}
\hline $\begin{array}{c}\text { Florencio } \\
\text { Varela }\end{array}$ & 9 & $6,98 \%$ & 7 & $12,73 \%$ & 0 & $0,00 \%$ & 16 & $5,16 \%$ \\
\hline $\begin{array}{c}\text { General San } \\
\text { Martin }\end{array}$ & 0 & $0,00 \%$ & 8 & $14,55 \%$ & 4 & $3,17 \%$ & 12 & $3,87 \%$ \\
\hline Hurlingham & 0 & $0,00 \%$ & 1 & $1,82 \%$ & 0 & $0,00 \%$ & 1 & $0,32 \%$ \\
\hline Ituzaingó & 0 & $0,00 \%$ & 1 & $1,82 \%$ & 0 & $0,00 \%$ & 1 & $0,32 \%$ \\
\hline José C. Paz & 32 & $24,81 \%$ & 7 & $12,73 \%$ & 0 & $0,00 \%$ & 39 & $12,58 \%$ \\
\hline La Matanza & 10 & $7,75 \%$ & 7 & $12,73 \%$ & 1 & $0,79 \%$ & 18 & $5,81 \%$ \\
\hline Lanús & 1 & $0,78 \%$ & 1 & $1,82 \%$ & 3 & $2,38 \%$ & 5 & $1,61 \%$ \\
\hline $\begin{array}{c}\text { Lomas de } \\
\text { Zamora }\end{array}$ & 1 & $0,78 \%$ & 1 & $1,82 \%$ & 3 & $2,38 \%$ & 5 & $1,61 \%$ \\
\hline $\begin{array}{c}\text { Malvinas } \\
\text { Argentinas }\end{array}$ & 4 & $3,10 \%$ & 0 & $0,00 \%$ & 0 & $0,00 \%$ & 4 & $1,29 \%$ \\
\hline Merlo & 2 & $1,55 \%$ & 0 & $0,00 \%$ & 0 & $0,00 \%$ & 2 & $0,65 \%$ \\
\hline Moreno & 7 & $5,43 \%$ & 5 & $9,09 \%$ & 0 & $0,00 \%$ & 12 & $3,87 \%$ \\
\hline Morón & 5 & $3,88 \%$ & 0 & $0,00 \%$ & 1 & $0,79 \%$ & 6 & $1,94 \%$ \\
\hline Quilmes & 2 & $1,55 \%$ & 7 & $12,73 \%$ & 19 & $15,08 \%$ & 28 & $9,03 \%$ \\
\hline San Fernando & 5 & $3,88 \%$ & 0 & $0,00 \%$ & 6 & $4,76 \%$ & 11 & $3,55 \%$ \\
\hline San Isidro & 1 & $0,78 \%$ & 0 & $0,00 \%$ & 25 & $19,84 \%$ & 26 & $8,39 \%$ \\
\hline San Miguel & 1 & $0,78 \%$ & 2 & $3,64 \%$ & 0 & $0,00 \%$ & 3 & $0,97 \%$ \\
\hline Tigre & 4 & $3,10 \%$ & 0 & $0,00 \%$ & 3 & $2,38 \%$ & 7 & $2,26 \%$ \\
\hline $\begin{array}{l}\text { Tres de } \\
\text { Febrero }\end{array}$ & 8 & $6,20 \%$ & 0 & $0,00 \%$ & 8 & $6,35 \%$ & 16 & $5,16 \%$ \\
\hline Vicente López & 2 & $1,55 \%$ & 0 & $0,00 \%$ & 8 & $6,35 \%$ & 10 & $3,23 \%$ \\
\hline Total & 136 & $\begin{array}{c}100,00 \\
\%\end{array}$ & 55 & $\begin{array}{c}100,00 \\
\%\end{array}$ & 126 & $100,00 \%$ & $\begin{array}{c}31 \\
7\end{array}$ & $\begin{array}{c}100,00 \\
\%\end{array}$ \\
\hline
\end{tabular}

Cuadro 9 - Obras de Infraestructura por Programa Federal según Municipio (en porcentajes y absolutos). Conurbano Bonaerense, 2014.

Fuente: Elaboración propia a partir de datos de la Subsecretaria de Desarrollo Urbano y Vivienda (SSDUyV), 2014.

\section{Reflexiones finales}

El presente artículo abordó los Programas Federales de Viviendas en el AMBA, proponiéndose dialogar con las políticas habitacionales en la región, buscando echar luz en torno a la implementación de la política pública que -tanto por los recursos destinados, como por las soluciones habitacionales producidas- restituyó la cuestión del hábitat, la vivienda y la infraestructura a la agenda pública en la Argentina. En ese marco, se observaron puntos de 
contacto con otros países de América Latina, tratándose de una política de hábitat que priorizo la construcción masiva de vivienda, fuertemente articulada en su implementación con iniciativas de mercado y sectores concentrados de la industria de la construcción.

Indagar la puesta en marcha de los Federales, implicó observar la situación habitacional que atraviesa el Conurbano Bonaerense, donde en base al Censo 2010 el 30,6\% (899.914) de los hogares se encuentra en condiciones deficitarias de vivienda, pero sólo el 3,9\% (114845) de los hogares habita una vivienda deficitaria irrecuperable - y entonces precisa una locación nueva-, mientras el 26,8\% (785.069) de los hogares habita una vivienda deficitaria recuperable o se encuentra en situación de hacinamiento -y entonces precisa el mejoramiento o la ampliación de su propia locación-. A su vez, otra aparición interesante que brindó el análisis fue el parque de viviendas particulares deshabitadas que existen en Conurbano, donde las mismas alcanzan 344.006. Al triangular estos valores con los datos presentados se observa que las viviendas deshabitadas alcanzarían para cubrir el 38,23\% del déficit habitacional. Más aún, si desagregáramos por tipo de déficit, y sólo tuviéramos en cuenta los hogares que ocupan viviendas precarias irrecuperables y aquellos que padecen hacinamiento pero habitan viviendas no precarias, las viviendas deshabitadas lograrían cubrir el total de los mismos. En ambos casos, la realidad habitacional pone en evidencia la necesidad de una política integral, donde la diversidad del déficit habitacional sea tenida en cuenta y el parque existente y deshabitado interrogado. Sin embargo, así como se ha descripto para las políticas habitacionales de la región, resulta indispensable resaltar la existencia de actores privados, protagonistas de la ejecución de estos proyectos, que se vieron favorecidos por la primacía de la vivienda nueva en los Federales: el sector vinculado a la industria de la construcción -las empresas constructoras y aquellas vinculadas a los rubros que producen insumos para la construcción- y los propietarios de tierra urbana o de tierra urbanizable -cuyos predios, ante el lanzamiento del programa, se vieron en creciente demanda, posibilitando el surgimiento de una lógica eminentemente especulativa-. En este sentido, se deberá interrogar si es posible coordinar una política habitacional integral, que al mismo tiempo se proponga beneficiar o reactivar sectores específicos de la economía.

En segundo lugar, para profundizar la lectura en clave urbana de las políticas de vivienda; resulta central observarla en relación a las estrategias públicas de intervención del mercado inmobiliario en particular y del mercado del suelo urbano en general. En esta línea, un punto crítico de la política federal, entre los años 2004 y 2014, es que ésta fue llevada a cabo sin ser necesariamente acompañada por una política de operación y producción de suelo urbano. En este punto, nuevamente se trata de una falencia que no se reduce a estas latitudes, sino que atraviesa la política habitacional a nivel regional; la ausencia de una mirada que articule la complejidad de los mercados de suelo con la problemática del acceso al suelo urbano se concretiza en el escaso desarrollo de políticas de tierra integradas a los programas de construcción de vivienda nueva en la región. 
En esta línea, resulta indispensable resaltar que la ausencia de una estrategia pública de intervención del mercado de suelo impacta directamente en la localización residencial intraurbana que será asignada a la vivienda social a partir de los Federales -y los programas afines en América Latina-. En este sentido, una de las tensiones centrales en la que se define la cuestión de la exclusión-inclusión urbano-habitacional es quién y cómo se apropia de la renta urbana generada por la acción del Estado y el colectivo social. Como ha sido señalado en trabajos anteriores, las intervenciones del Estado en el territorio producen importantes marcas en la vida cotidiana de las familias de sectores populares y en su hábitat, en tanto que contribuyen a definir estructuras de oportunidades para dar respuesta a los requerimientos de su vida cotidiana; de este modo, las oportunidades asociadas a la localización introducen importantes diferencias sociales entre los lugares de residencia y, también entre sus habitantes, constituyéndose en un factor crítico de estratificación socio espacial (DI VIRGILIO, 2011). La política federal de vivienda, entre los años 2004 y 2014, no supuso una ruptura con la lógica del mercado como mecanismo eficiente de asignación de localizaciones residenciales intra-urbanas; convocándonos a indagar si es posible generar territorios integrados, por esta vía, o por lo contrario se contribuye a su fragmentación y segmentación.

De este modo, el PFUVyA se vuelve una política paradigmática en el seno de los Federales, ya que al definir las villas y los asentamientos como los espacios para concretar la política habitacional, posibilitó que los gobiernos locales dispusieran de suelo urbano para implementar el PFCV y, a su vez, estimuló que el Estado Nacional y Provincial actuara en tierras ya elegidas y en barrios ya creados -y auto-urbanizados- por los sectores populares. Sin embargo, a partir de los datos analizados, se ha podido entrever que conforme nos alejamos de la ciudad central, la opción por proyectos habitacionales que priorizan la urbanización de villas o asentamientos disminuye abruptamente. Es decir, mientras en la primera corona, ante la falta de suelo urbano, el PFUVyA permitió destrabar la problemática, poniendo como sujeto del programa a las tierras ocupadas por villas o asentamientos; en la segunda corona, frente a la mayor disponibilidad de parcelas libres para la implementación de proyectos nuevos, los gobiernos locales parecieran haber dejado de lado la generación de alternativas de urbanización y planificación sobre el territorio, que posibilitasen resolver los problemas habitacionales vigentes en su territorio, para optar mayoritariamente por la construcción de viviendas nuevas.

\section{Referencias}

BETTATIS, Clarisa. De villa a "barrio": La (re)urbanización de villas y asentamientos. IN: CRAVINO, María Cristina (Org). Construyendo Barrios: Transformaciones socioterritoriales a partir de los Programas Federales de Vivienda en el Área Metropolitana de Buenos Aires (20042009). Buenos Aires: Ciccus, 2012. 
BOSELLI, Teresa; RODULFO, María Beatriz. Dilemas y desafíos de la política habitacional argentina desde un enfoque de derechos. Cuadernos de Vivienda y Urbanismo, Buenos Aires, v. 7, n. 14, p. 218-241, jul/dic. 2014.

CLICHEVSKY, Nora. Tierra vacante en ciudades latinoamericanas: Situación actual y propuestas para su utilización. El caso de Buenos Aires, Argentina. Buenos Aires: CONICETUBA-Lincoln Institute of Land Policy, 1999.

DEL RÍO, Juan Pablo; Duarte, Juan Ignacio. La gestión del suelo y la distribución de la ciudad. IN: CRAVINO, María Cristina (Org). Construyendo Barrios: Transformaciones socioterritoriales a partir de los Programas Federales de Vivienda en el Área Metropolitana de Buenos Aires (2004-2009). Buenos Aires: Ciccus, 2012.

DE SOUZA, Flavio; DE LA MORA, Luis; CAVALCANTI, Ana. Discursos y prácticas en la producción social del hábitat en Recife, Brasil: Políticas de mejora de vivienda, garantía de derechos y ampliación de diferencias. IN: DI VIRGILIO, María Mercedes; RODRÍGUEZ, María Carla (Org.). Producción social del hábitat: Abordajes conceptuales, prácticas de investigación y experiencias en las principales ciudades del Cono Sur. Buenos Aires: Café de las Ciudades, 2013.

DELGADILLO, Víctor. Urbanismo a la carta: teorías, políticas, programas y otras recetas urbanas para ciudades latinoamericanas. Cadernos Metrópole, San Pablo, v.16, n. 31, p. 89111 , jun. 2014.

DI VIRGILIO, Mercedes. El lugar de la vivienda social en la ciudad. Un análisis de la política habitacional desde el mercado de localizaciones intraurbanas y las trayectorias residenciales de los habitantes. Geograficando, La Plata, v.8, p. 295-301, 2014.

Di VIRGILIO, Mercedes; RODRÍGUEZ, María Carla; MERA, Gabriela. LA vivienda, un problema persistente: Las condiciones habitacionales en el Área Metropolitana de Buenos Aires. CIS, Santiago de Chile, p. $21-48,2016$.

HIDALGO DATTWYLER, Rodrigo. ¿Se acabó el suelo en la gran ciudad? Las nuevas periferias metropolitanas de la vivienda social en Santiago de Chile. EURE, Santiago de Chile, v. 33 , n. 98 , p. 57-75, may. 2007.

HIGUCHI HIRAO, Flavio; GUERREIRO, Isadora; FIORI ARANTES, Pedro; BARBOSA DE OLIVEIRA, Sandro. Reforma urbana y autogestión en la producción de la ciudad: Historia de un ciclo de luchas y desafíos para la renovación de su teoría y práctica. IN: DI VIRGILIO, María Mercedes; RODRÍGUEZ, María Carla (Org.). Producción social del hábitat: Abordajes conceptuales, prácticas de investigación y experiencias en las principales ciudades del Cono Sur. Buenos Aires: Café de las Ciudades, 2013.

INSTITUTO NACIONAL DE ESTADÍSTICA Y CENSOS. Censo 2010, 2010. Disponible en: http://www.indec.gov.ar/, consultado en Sep.2015.

OSTUNI, Fernando. Del FONAVI al Federal: Transformacionales socio-urbanas y respuestas estatales. Algunas reflexiones sobre la política habitacional. Buenos Aires: Centro de Documentación en Políticas Sociales y Subsecretaría de Gestión Social y Comunitaria Ministerio de DDHH y Sociales, 2007. 
Políticas nacionales y escenarios locales: Reflexiones sobre la implementación del Programa Federal de Construcción de Viviendas en la ciudad de Buenos Aires. Cuadernos de Vivienda y Urbanismo, Buenos Aires, v. 3, n. 5, p. 12-33, 2010.

PÍREZ, Pedro. La mercantilización de la urbanización. A propósito de los" conjuntos urbanos" en México. Estudios demográficos y urbanos del Colegio de México, México DF, v. 29, n. 3, p. 481-512, sep/dic. 2014.

RODRÍGUEZ, Alfredo; SUGRANYES, Ana. Vivienda Privada de Ciudad. Revista de Ingeniería, Bogotá D.C., v 32, p. 100-107, jun/dic. 2011.

RODRIGUEZ, Alfredo; SUGRANYES, Ana (Ed). Los con techo: un desafío para la política de la vivienda social. Santiago de Chile: Ediciones SUR, 2005.

RODRÍGUEZ, María Carla; DI VIRGILIO, María Mercedes. Caleidoscopio de las políticas territoriales. Buenos Aires: Prometeo, 2011.

SALAZAR, Clara. Suelo y política de vivienda en el contexto neoliberal mexicano. México DF: Colegio de México, 2014.

SUGRANYES, Ana et al. Derecho al suelo y la ciudad en América Latina: La realidad y los caminos posibles. Montevideo: Trilce, 2012.

VARELA, Omar; Fernández wagner, Raúl. Los Programas Federales de vivienda en el AMBA. IN: CRAVINO, María Cristina (Org). Construyendo Barrios: Transformaciones socioterritoriales a partir de los Programas Federales de Vivienda en el Área Metropolitana de Buenos Aires (2004-2009). Buenos Aires: Ciccus, 2012. 